\title{
ROMANIAN
}

NEUROSURGERY

Vol. XXXIV | No. $3 \quad$ September 2020

The Idiopathic Hypertrophic Spinal

Pachymeningitis.

A case report and review of literature

\author{
Surjeet Singh, \\ Stuti Kumari, \\ Abhijeet Sachan, \\ Satish Chandra Verma
}




\section{The Idiopathic Hypertrophic Spinal Pachymeningitis. A case report and review of literature}

\section{Surjeet Singh ${ }^{1}$, Stuti Kumari ${ }^{2}$, Abhijeet Sachan ${ }^{3}$, Satish Chandra Verma ${ }^{4}$}

\author{
${ }^{1}$ M.Ch. Neurosurgery, Department of Neurosurgery, SMS Medical \\ College and Hospital, Jaipur, Rajasthan, INDIA \\ 2 M.D. Pathology, Department of Pathology, Institute of Medical \\ Sciences BHU Varanasi, Uttar Pradesh, INDIA \\ ${ }^{3}$ M.Ch. Neurosurgery Department of Neurosurgery, SMS Medical \\ College and Hospital, Jaipur, Rajasthan, INDIA \\ ${ }^{4}$ M.Ch. Neurosurgery, Department of Neurosurgery, SMS Medical \\ College and Hospital, Jaipur, Rajasthan, INDIA
}

\begin{abstract}
Idiopathic hypertrophic spinal pachymeningitis (IHSP) is a rare inflammatory condition characterized by chronic inflammatory hypertrophy of the dura mater. It can involve the entire spine. However, most cases are reported in the cervical and thoracic spine. It can progress from local pain to radiculopathy and eventually develop myelopathy. The aetiology of IHSP is not known. However, it has been suggested to be associated with many diseases. Here we report a case of IHSP in 21year-old female who presented with paraplegia. The diagnosis was made on MRI Spine and histopathological examination. It was treated with surgical decompression, steroid therapy and patient improved gradually.
\end{abstract}

\section{INTRODUCTION}

Spinal IHP is a rare disease which causes chronic inflammatory hypertrophy of the duramater. Its etiology is still unknown. It most commonly involves cervical and thoracic spine1,2,3. Commonly presents in the age of 6 th and 7 th decade of life4. Symptoms arises due to progressive compression of adjacent structures. We report a rare case of IHSP in a 21 year old women who presented with paraplegia.

\section{CASE REPORT}

A 21 years old female presented with history of progressive weakness of bilateral lower limb since $2 \frac{1}{2}$ months, was admitted in department of neurosurgery, SMS hospital jaipur. On examination, modified Ashworth scale of spasticity was grade 2 in bilateral lower limb, Medical Research

\section{Keywords \\ chronic inflammatory spinal pachymeningitis, idiopathic, paraplegia, cord compression}

$\triangle$

Corresponding author: Surjeet Singh

Department of Neurosurgery, Sawai Man Singh Medical College Jaipur, Rajashthan, India

sujitgmc35@gmail.com
Copyright and usage. This is an Open Access article distributed under the terms of the Creative Commons Attribution Non-Commercial No Derivatives License (https://creativecommons org/licenses/by-nc-nd/4.0/) which permits noncommercial re-use, distribution, and reproduction in any medium, provided the original work is unaltered and is properly cited.

The written permission of the Romanian Society of Neurosurgery must be obtained for commercial re-use or in order to create a derivative work.

ISSN online 2344-4959

(C) Romanian Society of Neurosurgery

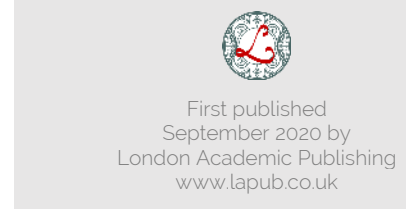


Council power grade was $0 / 5$ in both lower limb, bilateral Knee and ankle reflex was +3 . Bilateral Babinski sign was positive and superficial abdominal reflex was absent. 70-80 \% sensory loss of all modality below $\mathrm{T} 2$ dermatome level was present bilaterally. Other systemic examinations were normal. MR imaging of the thoracic spine demonstrated an intradural extramedullary lesion extending from C7-D4 level that was hyperintense on $\mathrm{T} 1$ and hypointense on $\mathrm{T} 2$ and nonenhancing on contrast. The lesion was compressing the spinal cord with cord edema. All routine hematological investigations were within normal limit. All the relevant investigations related to the cause of spinal pachymeningitis were negative. After D1-D5 laminectomy, duramater was found to be thickened compressing spinal cord. Posterior excision of duramater was done. A Durafoam was placed posteriorly to expand the thecal sac and specimen was sent for histopathological examinations. Chronic inflammation with lymphoplasmacytic infiltrate and fibrosis was found on histology. Postoperative steroid therapy was given. patient was under follow up and after 8 months, patient developed some sensation in both lower limb and power of lower limb improved from $0 / 5$ to $2 / 5$.
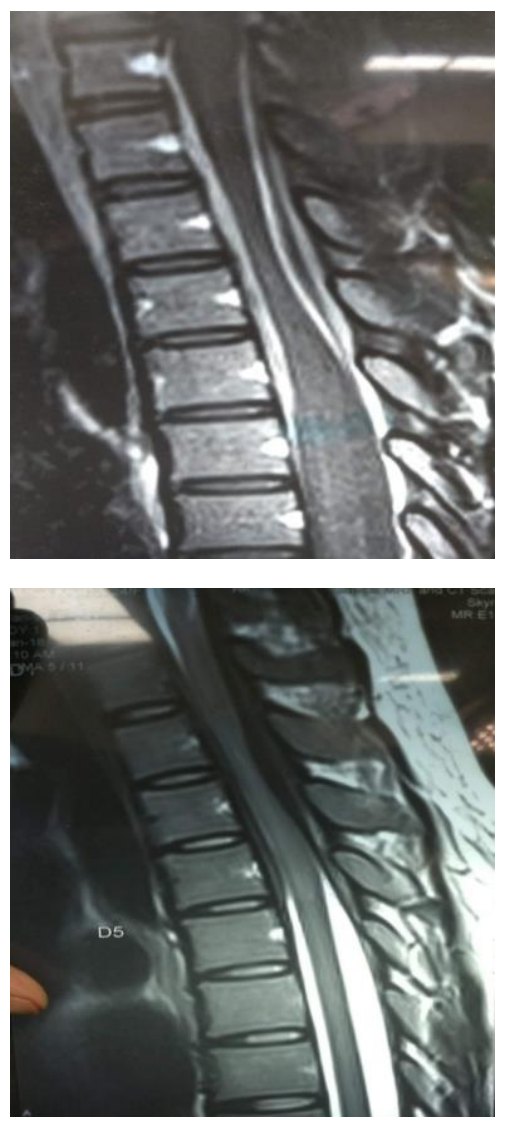

Figure 1. MRI Cervico-dorsal Spine sagittal preoperative

(A) T1 image- $A$ hyperintense intradural

extramedullary lesion present at C7D4, compressing the spinal cord. (B) T2 image- $A$ hypointense intradural

extramedullary lesion present at C7D4, compressing the spinal cord.

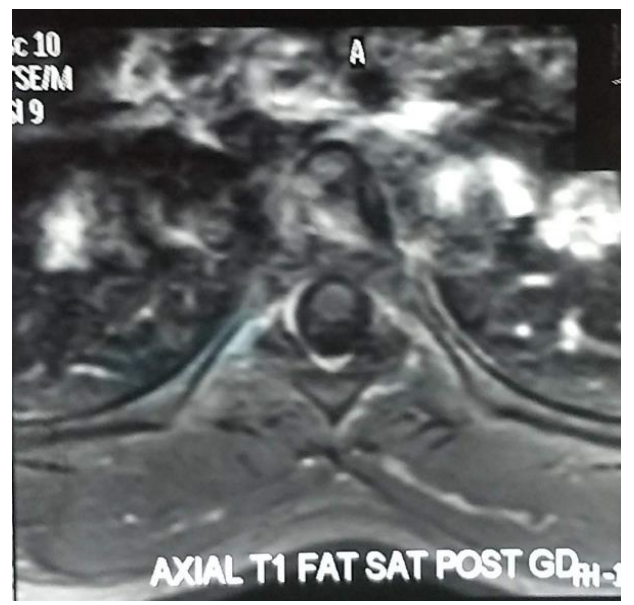

Figure 2. MRI Cervicodorsal Axial image post contrast: (A)

Minimal enhancing intradural extramedulla

ry lesion

present

posterior to spinal cord

(B) $\mathrm{T} 2$

weighted image-

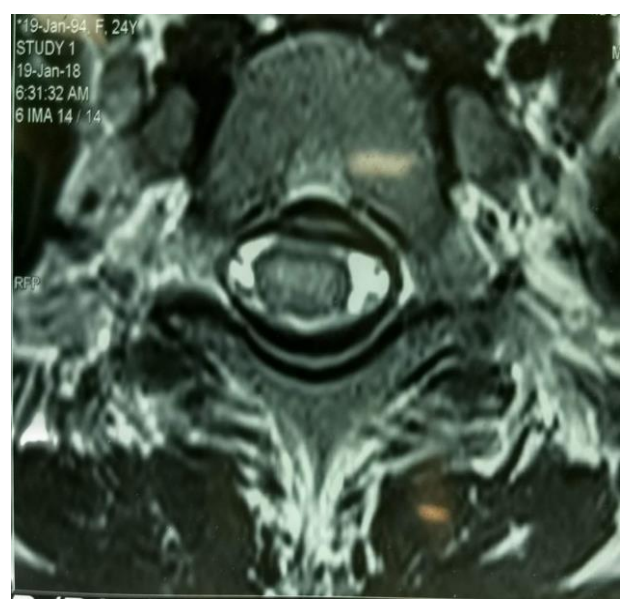

Hypointense lesion present posterior to spinal cord.

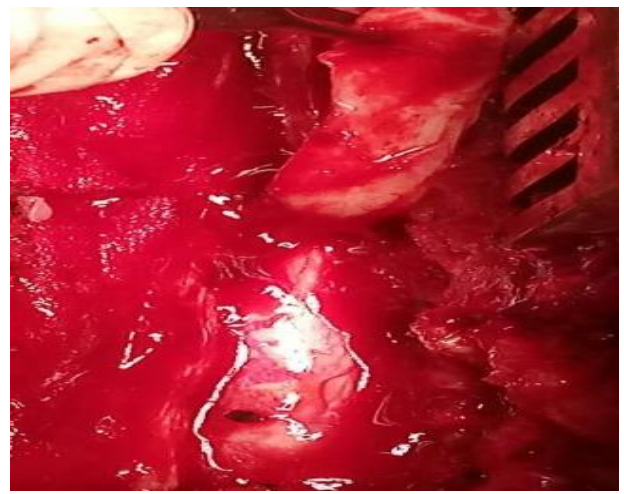

Figure 3. (A)

Intraoperativ e image showing a grossly thickened dura (B)

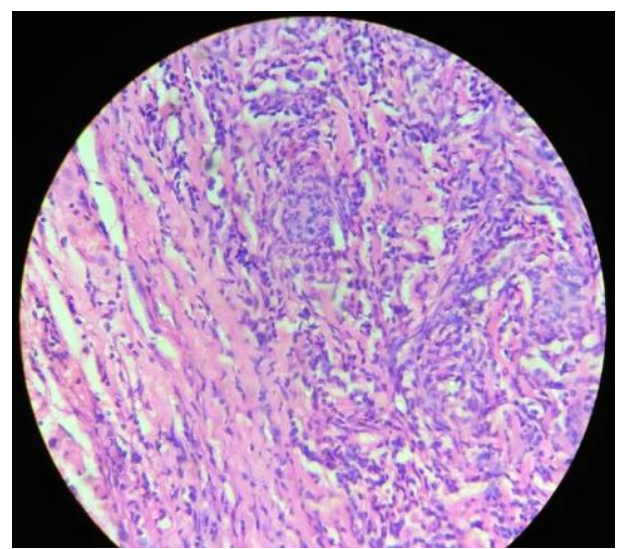

histopatholo gical examination s showing fibrocollagen ous tissue with dense infiltrate of lymphocytes and plasma cells. 


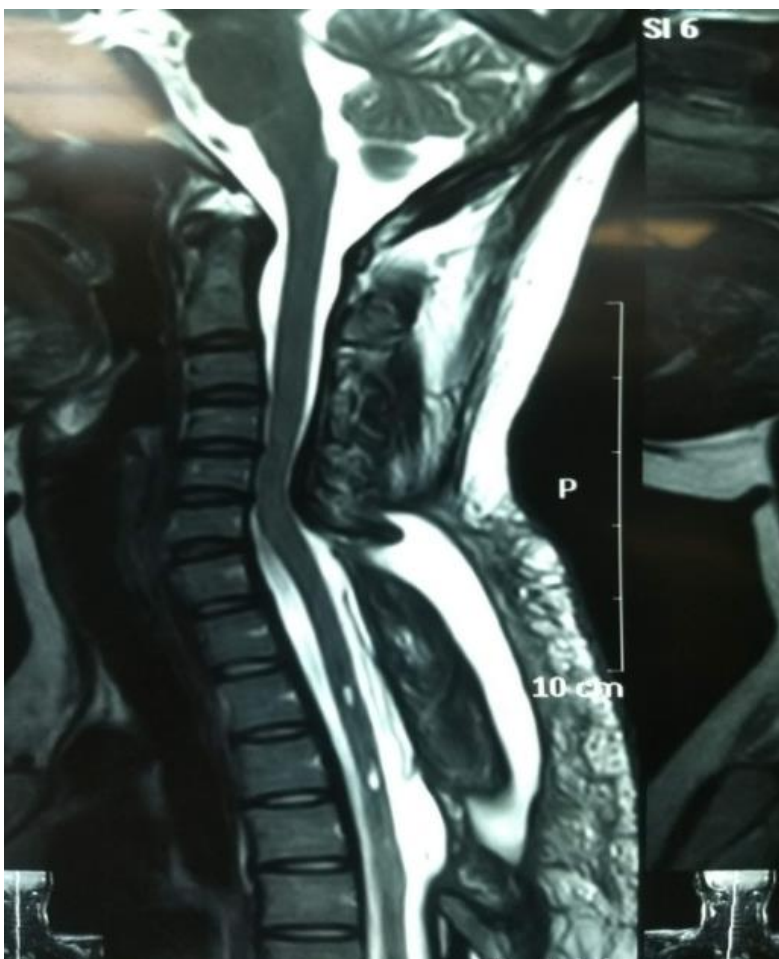

Figure 4. Postoperative MRI of the cervico-dorsal spine, sagittal view: showing the expanded cord.

\section{DISCUSSION}

This disorder is rare and usually found intracranially and spinal form is extremely rare ${ }^{5-8}$. Friedman $D$ et al found most cases of IHP intracranially ${ }^{2}$. It usually involves the cervical and thoracic dura or occurs as a craniospinal form ${ }^{(5,9,10)}$. The first case of spinal IHSP was reported by Charcot and Joffroy named as "Pachymeningitis hypertrophica cervicalis" in $1869^{(11,12)}$. Spinal IHSP is a rare cause of nerve root and spinal cord compression. It has been implicated in variety of inflammatory and infectious processes like tuberculosis, sarcoidosis, rheumatoid arthritis, wegener granulomatosis etc. ${ }^{(5-8)}$. So, other possibilities need to be ruled out as IHSP is a diagnosis of exclusion ${ }^{(5-7)}$. In our case, we could not find any predisposing illnesses such as infectious diseases or autoimmune diseases in spite of thorough investigations. Joffroy and Rosenfeld et al, described three stages; local and radicular pain in first stage. Signs of nerve root compression in second stage and spinal cord compression was described in third stage ${ }^{(12,13)}$. Haobin chen et al, reported age of the patients ranges from 28 years to 68 years (median age 56 years), and female being more commonly affected (male/female ratio: 6:9). Thoracic spine being most commonly affected followed by cervical and lumbar spine ${ }^{14}$. Friedman $D$ and Flanders described peripheral enhancement on MRI which was present in all 3 patients as highly suggestive of hypertrophic pachymeningitis, which was also noted in another report ${ }^{2}$. Dumont AS and S.Pai et al, proposed extramedullary mass extending over multiple vertebral levels, strongly hypointense signal on T2- weighted images, and variable peripheral margin enhancement are suggestive of the IHSP ${ }^{15,16}$. In our case, extramedullary lesion was present in C7-D4 level which was hypointense on T2weighted image and hyperintense on $\mathrm{T} 1$ weighted image. spine. Martin N et al reported good result of methotrexate treatment in cranial pachymeningitis ${ }^{7}$. Treatment choices for IHSP include surgical decompression, administration of corticosteroids, radiation therapy, and immunosuppressive agents but relapses are common ${ }^{(5,17)}$. Surgical decompression provides some relief, and early surgical intervention can successfully alleviate neurologic sequelae ${ }^{1,9,10}$. Naffziger and Rosenfeld et al, recommended surgical decompression by laminectomy and excision of the involved dura for its management $(13,15,18)$. Dumont AS and Kitai Ret al reported that biopsy with steroid therapy can reduce the thickness of the dura and can improve neurologic deficit ${ }^{(15,19)}$.Naffziger and Dumont et al suggested laminoplasty instead of extensive laminectomy because it reduce back pain and increase spinal stability ${ }^{(15,18)}$.In our case C7-D4 laminectomy with dural excision was done and post-operative steroid therapy was administered. After 8 months, power of lower limb improved from $0 / 5$ to $2 / 5$.

\section{CONCLUSION}

We reported a rare case of cervico-dorsal compressive myelopathy caused by IHP. Definite diagnosis needs thorough blood investigations, radiological and histopathological findings as IHSP is a diagnosis of exclusion. Surgical decompression along with steroid therapy can be considered as an effective mode of treatment. Early diagnosis and treatment can lead to better neurological outcomes.

\section{CONFLICT OF INTERESTS}

The authors declare no conflict of interests.

ABBREVIATIONS AND ACRONYMS

IHSP: Idiopathic hypertrophic spinal pachymeningitis; IHP: Idiopathic hypertrophic pachymeningitis; MRI: Magnetic resonance imaging. 
Table 1. Idiopathic hypertrophic pachymeningitis - Age, location, mode of treatment and its response.

\begin{tabular}{|l|l|l|l|l|l|}
\hline Author ${ }^{\text {Ref no. }}$ & Age & Sex & location & Treatment & Outcomes \\
\hline Pai et al ${ }^{16}$ & 68 & $\mathrm{~F}$ & Spinal: C6, C7 & Laminectomy, steroid & $\begin{array}{l}\text { spontaneous temporary } \\
\text { resolution of symptoms, } \\
\text { recurrence after surgery }\end{array}$ \\
\hline Takahashi et al ${ }^{20}$ & 67 & $\mathrm{M}$ & Spinal C3, C7 & $\begin{array}{l}\text { Corticosteroid } \\
\text { patient could walk } \\
\text { independently }\end{array}$ \\
\hline${\text { Ranasinghe et al }{ }^{21}}^{21}$ & 65 & $\mathrm{M}$ & Spinal T7, T8 & $\begin{array}{l}\text { Laminectomy, } \\
\text { Corticosteroids }\end{array}$ & MRI improvement at 57 months \\
\hline Yasuda et al22 & 28 & $\mathrm{M}$ & $\begin{array}{l}\text { Spinal: T1, T4, } \\
\text { then L1, L3 }\end{array}$ & $\begin{array}{l}\text { Laminectomy, } \\
\text { Corticosteroids }\end{array}$ & Recovered \\
\hline Lai et al ${ }^{23}$ & 41 & $\mathrm{M}$ & Spinal T2, T4 & $\begin{array}{l}\text { Laminectomy, dura } \\
\text { excision }\end{array}$ & Unavailable \\
\hline Present study & 21 & $\mathrm{~F}$ & Spinal C7-D4 & $\begin{array}{l}\text { Laminectomy, dura } \\
\text { excision }\end{array}$ & Partial Recovery \\
\hline
\end{tabular}

\section{REFERENCES}

1. Botella C, Orozco M, Navarro J, et al. Idiopathic chronic hypertrophic craniocervical pachymeningitis: case report. Neurosurgery 1994;35:1144-49.

2. Friedman D, Flanders A, Tartaglino L: Contrast-enhanced MR imaging of idiopathic hypertrophic craniospinal pachymeningitis. AJR Am J Roentgenol 160:900-901, 1993.

3. Hassin GB: Histogenesis of cerebral hypertrophic pachymeningitis and its relation to syphilis. Am J Syphilis 2:715, 1918.

4. Mikawa $Y$, Watanabe R, Hino Y, Hirano K: Hypertrophic spinal pachymeningitis. Spine (Phila Pa 1976) 19:620625, 1994.

5. Kupersmith MJ, Martin V, Heller G, Shah A, Mitnick HJ: Idiopathic hypertrophic pachymeningitis. Neurology 62:686- 694, 2004.

6. Lee YC, Chueng YC, Hsu SW, Lui CC: Idiopathic hypertrophic cranial pachymeningitis: case report with 7 years of imaging follow-up. AJNR Am J Neuroradiol 24:119-123, 2003.

7. Martin N, Masson C, Henin D, et al. Hypertrophic cranial pachymeningitis: assessment with $\mathrm{CT}$ and MR imaging. AJNR Am J Neuroradiol 1989;10:477-84.

8. Riku S, Kato S. Idiopathic hypertrophic pachymeningitis. Neuropathology 2003;23:335-44.

9. Ashkenazi E, Constantini S, Pappo O, et al. Hypertrophic spinal pachymeningitis: report of two cases and review of the literature. Neurosurgery 1991;28:730 -32.

10. Mikawa Y, Watanabe R, Hino W, et al. Hypertrophic spinal pachymeningitis. Spine 1994;19:620 -25.

11. Charcot JM, Joffroy A. Deux cas d'atrophie musculaire progressive avec le' - sions de la substance grise et des faisceaux ante' rolate' raux de la moelle e' pinie' re. Arch Physiol Norm Pathol 1869;2:354 -67, 629 -49, 744 -69.

12. Joffroy A. Deux cas d'atrophie musculaire progressive avec lesions de la substance grise et des faisceaux anterolateraux de la moelle epiniere. Arch Physiol Norm Path. 1869;2:354-367.

13. Rosenfeld JV, Kaye AH, Davis S, Gonzales $M$. Pachymeningitis cervicalis hypertrophica. Case report. J Neurosurg. 1987;66:137-139.

14. Haobin Chena, Yulong Lib, Nikita Mehraa, Sheela Mehraa, David Frescoc, Joseph Paula, Chi P Cheunga, d. Idiopathic Hypertrophic Pachymeningitis as a Rare Cause of Spinal Cord Compression.Jornal of medical cases. Volume 3, Number 4, August 2012, pages 267-269.

15. Dumont AS, Clark AW, Sevick RJ, Myles ST. Idiopathic hypertrophic pachymeningitis : a report of two patients and review of the literature. Can J Neurol Sci. 2000;27:333-340.

16. Pai $\mathrm{S}$, Welsh $\mathrm{CT}$, Patel $\mathrm{S}$, Rumboldt Z. Idiopathic hypertrophic spinal pachymeningitis : report of two cases with typical mr imaging findings. AJNR Am J Neuroradiol. 2007;28:590-592.

17. Smucker JD, Ramme AJ, Leblond RF, Bruch LA, Bakhshandehpour G. Hypertrophic spinal pachymeningitis with thoracic myelopathy: the initial presentation of ANCA-related systemic vasculitis. J Spinal Disord Tech 2011;24(8):525-532.

18. Naffziger HC, Stern WE: Chronic pachymeningitis; report of a case and review of the literature. Arch Neurol Psychiatry 62:383-411, 1949.

19. Kitai R, Sato K, Kubota T, Kabuto M, Uno H, Kobayashi H. Hypertrophic cranial pachymeningitis involving the pituitary gland : a case report. Surg Neurol. 1997;48:5862. discussion 62-63.

20. Hiroshi Takahashi, Akihito Wada, Yuichiro Yokoyama, Maki Ishii, Kazutoshi Shibuya, Toru Suguro. Idiopathic hypertrophic spinal pachymeningitis: a case report. Journal of Orthopaedic Surgery, 2010, 18(1), 113- 117.

21. Moksha G. Ranasinghe, Omar Zalatimo, Elias Rizk, Charles S. Specht, G. Timothy Reiter, Robert E. Harbaugh, and Jonas Sheehan. Idiopathic hypertrophic spinal 
pachymeningitis Report of 3 cases. J Neurosurg Spine, 2011, 15, 195-201.

22. Mio Tsutsui. Taketoshi Yasuda. Masahiko Kanamori. Takeshi Hori.Tomoatsu Kimura. Long-term outcome of idiopathic hypertrophic thoracic Pachymeningitis. Eur Spine J, 2012, 21 (4), 404-407.
23. Hui-Ting Hsu, Shu-Shong Hsu, Chu-Chun Chien, PingHong Lai. Teaching Neurolmages: Idiopathic hypertrophic spinal pachymeningitis mimicking epidural lymphoma. Neurology, 2015, 84, 67-68. 